--مجلة علوم الرافدين، المجلد 27، العدد 4 / عدد خاص بالمؤتمر العلمي الثالث لعلوم الحياة ، ص 1-16، 2018---

تأثير بعض العوامل البايولوجية في إمراضيه بعض فطريات الجذور لصنفي الشليك (الفراولة) Festival هابل Hapil (Fragaria x ananassa Duch.)

$$
\text { قدم علويل احمد العامري" }
$$

*E-mail : $\underline{\text { Biol.Haeel_78@ Yahoo.com }}$

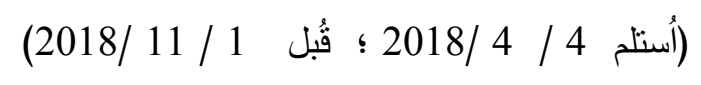

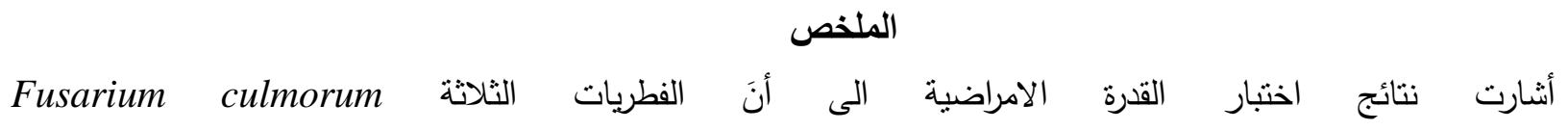
و. Bipolaris spp. Cylindrocarpon spp و تسبيت في ظهور الأعراض المرضية في صنفي الثليك هابل Hapil وفستفل Festival وكان الصنف هابل اكثر حساسية من الصنف فستفل تجاه الفطريات الثلاثة المدروسة، فقد بينت النتائج الى ان إضافة المقاومين الحيويين الفطري Trichoderma harzianum والبكتيري Pseudomonas aerogenosa والمقاوم الكيميائي Azadirachtin الفى الفطريات الثلاثة Cylindrocarpon spp. F. culmorum و. Bipolaris spp اعطى انخفاضاً معنوياً في شدة ظهور المرض بالمقارنة مع الفطريات كلاً على حدة وبمفرده. وكان للمقاوم الحيوي الفطري كفاءة تضادية عالية ضد الفطريات

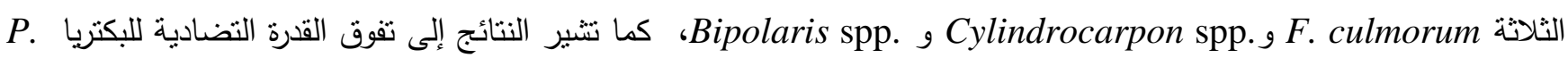
على الفطر aerogenosa على الفطر .Cylindrocarpon spp.

الكلمات الدالة: الثليك، فطريات، الجذور، Pseudomonas aerogenosa، Trichoderma harzianum .

\title{
Effect of some Biological Agents on Pathogenicity of some Root Pathogenic Fungi on Two Strawberry Varities (Fragaria $\mathrm{x}$ ananassa Duch.) Hapil and Festival
}

\author{
Hadeel A. AL-Ameri \\ Department of Biology \\ College of Science \\ University of Mosul
}

\author{
Zuhair A. Dawood \\ Department of Horticulture \\ College of Agriculture and Forestry \\ University of Mosul
}

\author{
Fatin N. Mula Abed \\ Department of Biology \\ College of Science \\ University of Mosul
}

\begin{abstract}
Results of pathogenicity showed that the three fungi Fusarium culmorum, Cylindrocarpon spp. and Bipolaris spp. were the faster fungi inoculated in the emergence of symptoms as pathological symptoms in both strawberry varities Hapil and Festival. Hapil was more sensitive than Festival agents on the three studied fungi. The results indicate that the addition of biological agent $T$. harzianum and $P$.
\end{abstract}




$$
\text { هديل احمد العامري وآخرون }
$$

aerogenosa and fungicides Azadirachtin to the three fungi $F$. culmorum, Cylindrocarpon spp. and Bipolaris spp. caused a significant reduction of the pathogenicity compared with fungi alone, and the results indicated that the biological agent efficiency of high antagonisms ability against the three fungi F. culmorum, Cylindrocarpon spp. and Bipolaris spp., and the results indicated the ability of biological agent on $P$. aerogenosa agents the fungus Cylindrocarpon spp., and fungicide Azadirachtin showed high antagonism against Cylindrocarpon spp.

Keywords: Strawberry, Fungi, Root, Trichoderma harzianum, Pseudomonas aerogenosa.

\section{المقدمة}

تعد المسببات المرضية الفطرية المتوطنة في التربة من اكثر الفطريات ضررا بالمحاصيل الزراعية ويسبب معظمها امراض تعفن البذور والجذور ، وتظهر اعراضها على المجموع الخضري بعدما تكون قد تمكنت من احداث ضرر بالمجوع الجذري ومما يزيد

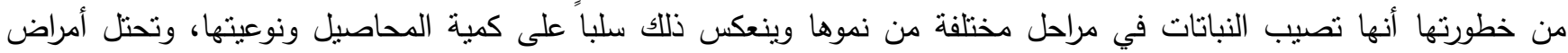
الجذور منضمنة الذبول الوعائي جانباً مهماً في تدهور الإنتاج النباتي نوعاً وكماً، بخاصة في النباتات الحساسة ضد هذه هذه الأمراض كالنباتات الحولية والمعمرة اذ تصيب ممرضات الجذور النبات في جميع مراحل نموه من الإنبات حتى الإزهار (Agrios، 2005). ان تعفن جذور الثليك شائع في المزارع الدائمة وأظهر العزل عن النباتات المصابة العديد من مسببات الأمراض منل الإن ‘Moročko) Pythium spp. و Rhizoctonia solani و Phoma spp. و Fusarium spp. و Cylindrocarpon spp. 2006)، وارتبط الفطر Macrophomina phaseolina مع خسائر تعفن التاج الخطيرة في نباتات الثليك في استراليا في السنوات الأخيرة (Don et al., 2013). وذكر Manici et al., 2005 انه أجريت دراسات عدة في ايطاليا لمعرفة مكونات التربة الميكروبية Cylindrocarpon التي تسبب تعفن الجذر الاسود في الثليك الذي يحدث في جميع أنحاء إيطاليا وهذه الفطريات هي Fusarium oxysporum و destructans

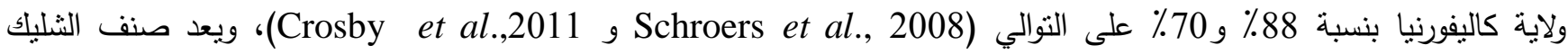
Cylindrocarpon و F. oxysporium أكثر عرضة للذبول والإصابات المرتبطة بالتاج والجذر المنسبب عن الفطر Camarosa .(Fang et al., 2012) destructans وبسبب زيادة كلف استخدام المواد والأسمدة الكيميائية واضرارها على صحة الانسان والحيوان توجه معظم الباحثين الى المقارنة بين الاسمدة الكيميائية والفطريات والبكتريا المحفزة لنمو النبات على محاصيل عديدة بوصفها عوامل مكافحة حيوية، وزاد الاهتمام بموضوع المكافحة الاحيائية للسبطرة على الآفات الزراعية بشكل عام ومسببات امراض النبات بشكل خاص في العراق، ولاسيما بعد نجاحها في مكافحة بعض المسببات المرضية بكفاءة عالية مقارنة مع المبيدات الكيميائية، ويعد محصول الثليك من المحاصيل المهمة التي بدأت تدخل بشكل ملحوظ في مختلف مناطق العراق خاصة الثمالية منها لعدم اتباع المزارعين برامج وقائية منتظمة لتقليل شدة الاصابة بفطريات التربة وانخفاض معدل الإنتاجية قياساً الى الدول المجاورة والعالم. 
عزلت الفطريات Bipolaris spp. و من ثلاثة اصناف من نبات الثليك المصابة بالفطريات وهي الصنف سويت شارلي Sweet charli والصنف هابل Hapil والصنف فستفل Fistavil المزروعة في الظلة الخشبية التابعة لقسم البستنة وهندسة الحدائق/ كلية الزراعة والغابات جامعة الموصل ومن ثلاث مناطق من الثتلة هي الجذور والمدادات والتاج، شخصت حسب المفاتيح التصنيفية المعتمدة Ellis, 1971؛ Domsch et al.,1980 ؛ .(Pitt and Hocking, 2007 ؛ Leslie and Summerebll, 2006 ؛ Nelson et al.,1983

Tصدر المقاوم الحيوي الفطري Tarzianum تم الحصول على المقاوم الحيوي الفطري T. harzianum من قسم وقاية النبات، كلية الزراعة والغابات، جامعة الموصل بشكل مسحوق زرع على وسط PDA للحصول على غزل فطري نشيط للعزلة استخدم كمقاوم حيوي فطري. Pصدر المقاوم الحيوي البكتيري Pصي وسن تم الحصول على عزلة البكتريا P. aerogenosa من بنك السلالات البكتيرية في قسم علوم الحياة/كلية العلوم جامعة الموصل واستخدمت كمقاوم حيوي بكتيري.

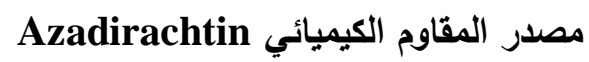
المقاوم الكيميائي Azadirachtin من انتاج مختبرات د. راج/الهند بشكل معلق تركيزه 5\%.

حساسية اصناف الثليك للفطريات Cylindrocarpon spp.،F.culmorum و. Bipolaris spp تم اجراء العدوى الصناعية بالفطريات Bipolaris spp. Cylindrocarpon spp. ،F.culmorum ولاختبار حساسية صنفي الثليك هابل وفستفل (تم الحصول على شتلات صنف الثليك هابل من نباتات الأمهات المزروعة في الظلة الخشبية في مشتل

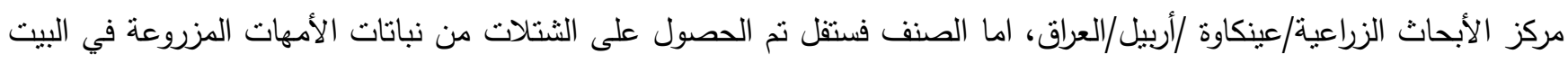
البلاستيكي في مشروع البطاطا والطماطة التابع لوزارة الزراعة/الموصل/العراق) تجاهها في البيت البلاستيكي غير المدفأ، وفق تصميم نيات القطاعات العشوائية الكاملة بثلاثة مكررات كل مكرر ستة سنادين، وذللك بخلط التربة بالبتموس وبمعدل 1 : 4 (بتموس: نربة مزيجية غرينية) ثم تعقيمها بالفورمالين وغطيت لمدة خمسة ايام بعدها جرى تقليبها كل يوم لمدة عشرين يوماً للتخلص من بقايا الفورمالين والنواتج المتحللة من عملية التعقيم،

تم تلويث تربة الآصص (قطر 22 سم وارتفاع 25 سم اذ احتوى الآص الواحد على 5 كغم تربة مزيجية غرينية معقمة بالفورمالين بنسبة 1\%) تبعاً لطريقة Saydam واخرين (1973) وذلك بتقطيع النموات الفطرية المزروعة على وسط PDA والمحضنة في درجة 28º لمدة اسبوع الى قطع صغيرة وخلطها بالطبقة السطحية لتربة السنادين وتركت لمدة ثلاثة ايام. بعدها زرعت شتلات الثليك للأصناف المدروسة اما معاملة المقارنة فتمثلت بزراعة الثتلات في نربة غير ملوثة بالفطريات، نفذت هذه التجربة في كلية العلوم/قسم علوم الحياة/جامعة الموصل/العراق وفق تصميم القطاعات العشوائية الكاملة بثلاثة مكررات لكل معاملة كل مكرر سندانة واحدة وسقيت السنادين حسب الحاجة وتكونت التجربة من المعاملات الاتية لكل من صنفي الثنليك هابل وفنتفل :

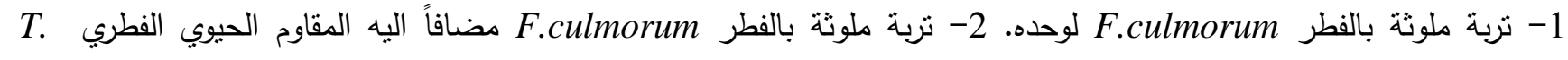

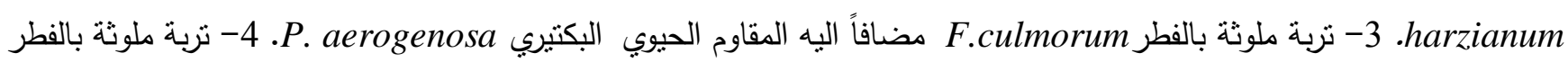

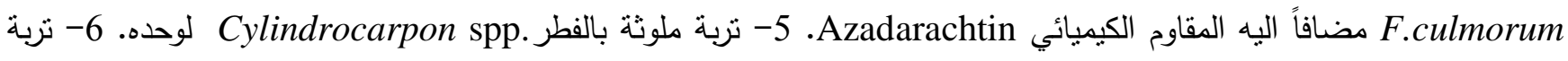




$$
\text { هديل احمد العامري وآخرون }
$$

ملوثة بالفطر . Cylindrocarpon spp. مضافاً اليه المقاوم الحيوي الفطري 7. harzianum Cylindrocarpon بالفطر Cylindrocarpon spp مضافاً اليه المقاوم الحيوي البكتيري P. aerogenosa

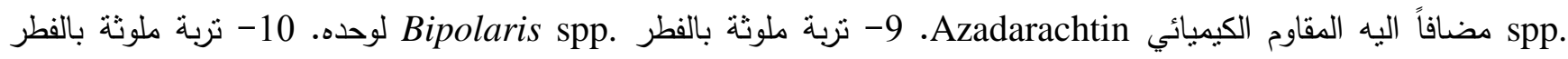

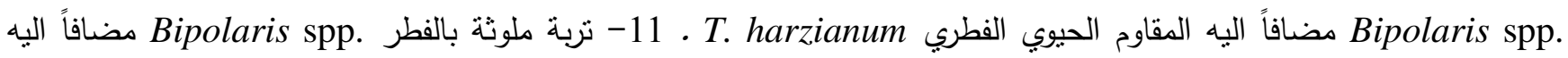

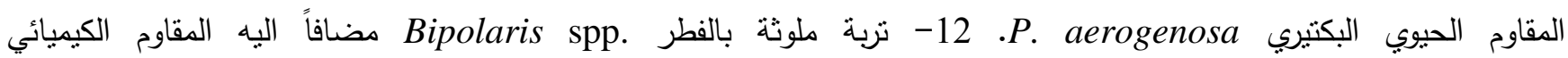
.Azadarachtin 13- تربة ملوثة بالمقاوم الحيوي الفطري T. Aarzianum لوحده. 14- نربة ملوثة بالمقاوم الحيوي البكتيري P. Aerogenosa

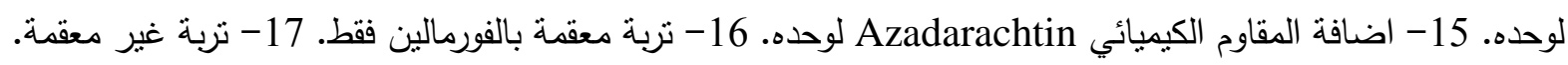
ثم اضيف سماد نيتروجيني بعد زراعة الثتلات بدفعتين الدفعة الأولى في 2013/2/3 وبمعدل 5 غم لكل سندانة، أما الدفعة الثانية من السماد فأضيف في 2013/4/3. وتم ش السماد الورقي Blue filed (المجز من شركة Blue filed البلجيكية) لمرة واحدة فقط في 2013/2/3 وكنلك جرى

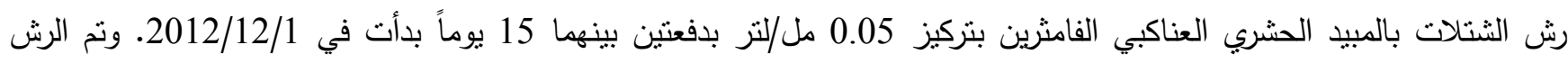

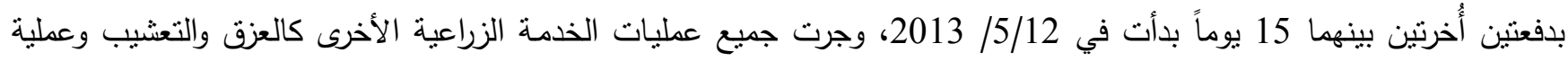
الري بصورة اعتبادية حسب حاجة النبات للماء وبثكل ثابت اذ نروى الثتلات (مرتين في الأسبوع) في الأيام الاعتبادية، أما في الأيام الحارة في الصيف فيتم الري مرة واحدة في اليوم. وتم متابعة تسجيل نتائج ظهور الأعراض المرضية الخاصة بكل فطر ومقاوماته الحيونة الحية والكيميائية ومقارنتها مع نتائج الأعراض المرضية الاولية واختبار القدرة الإمراضية في موسم زراعي كامل. وزرعت شتلات صنفي الثنليك بناريخ 2012/9/13 واستمرت التجربة موسما زراعيا كاملا حتى 2013/5/31 2013، واضيف

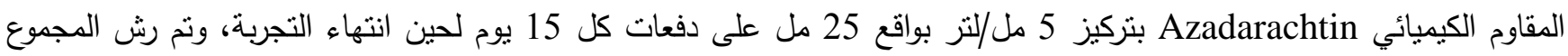
الخضري بالعالق البوغي Bipolaris spp. بعد 30 يوما من تأريخ زراعة الثتلات، وتم اعتماد

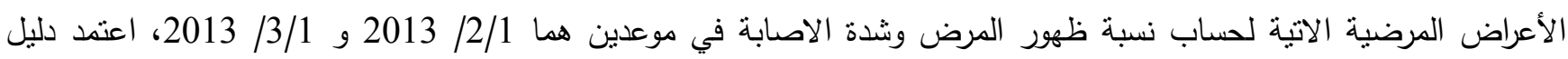
الاصابة التالي للفطرين Cylindrocarpon spp. و F.culmorum كما في (الجدول 1):

الجدول 1 :الدليل المرضي لحساب شدة الاصابة للفطريات Cipolaris spp. و و F.culmorumdrocarpon spp. و

\begin{tabular}{|c|c|c|c|}
\hline \multicolumn{2}{|l|}{$\begin{array}{c}\text { الفطر } \\
\text { Bipolaris spp. }\end{array}$} & \multicolumn{2}{|l|}{$\begin{array}{c}\text { F.culmorum و و. الفطرين } \\
\text { Cylindrocarpon spp }\end{array}$} \\
\hline الأعراض ال & الاصلية & | الأعراض | | | | & دليل الاصابة \\
\hline نبات سليم دون ظهور أعراض مرضية عليه & 0 & نبات سليم دون ظهور أعراض مرضية عليه & 0 \\
\hline وضوح العروق على أوراق النبات نتيجة الاصابة & 1 & وضوح العروق على أوراق النبات نتيجة الاصابة & 1 \\
\hline اصفرار فاتح لأوراق النبات & 2 & اصفرار أوراق النبات & 2 \\
\hline اصفرار منوسط لأوراق النبات & 3 & احتراق حوافِ الأوراق & 3 \\
\hline اصفرار غامق لأوراق النبات & 4 & انحناء الأوراق الى الاعلى & 4 \\
\hline انحناء الأوراق الى الاعلى & 5 & موت الأوراق والوريقات & 5 \\
\hline
\end{tabular}




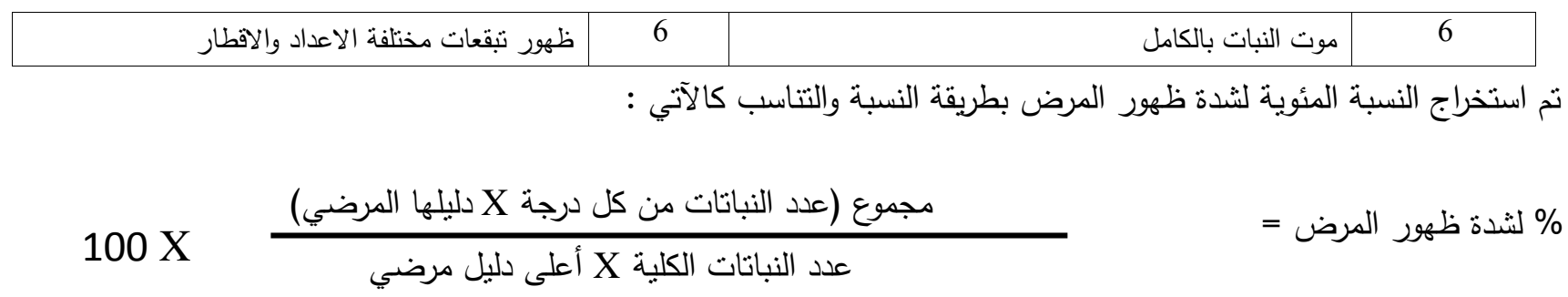

وتم حساب عدد البقع في المعاملات المصابة صناعياً بالفطر .Bipolaris spp ومقاوماته الحيوية والكيميائية بطريقة العد. كما تم حساب متوسط اقطار البقع في المعاملات المصابة صناعياً بالفطر .Bipolaris spp ومقاوماته الحيوية والكيميائية لكل المكررات في الوحدة التجريبيه باستخدام المسطرة.

\section{النتائج والمناقشة}

حساسية اصناف الثليك للفطريات Cylindrocarpon spp.culmorum و و Bipolaris spp F.culmorum أظهرث النتائج في الثكل (1) ان الصنف هابل اكثر حساسية من الصنف فستفل تجاه الفطريات الثلاثة و. Bipolaris spp. Cylindrocarpon spp ولى الرغم من موت جميع الشتلات في كل المكررات في المعاملة بالفطر

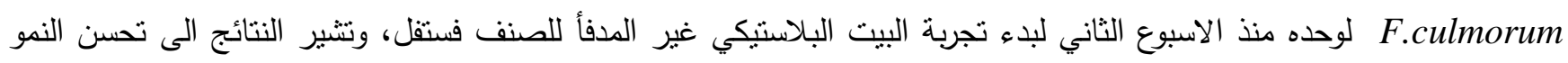
الخضري في المعاملة بالفطر F.culmorum مضافاً اليه المقاوم الحيوي الفطري والمعاملة بالفطر . Cylindrocarpon spp مضافاً اليه المقاوم الحيوي البكتيري والمعاملة بالفطر . Bipolaris spp. مضافاً اليه المقاوم الحيوي الكيميائي مقارنة بالمعاملة بالفطريات الثناثة كلاً على حدة وكذلك المعاملة بتربة معقمة بالفورمالين والمعاملة بنربة غير معقمة في صنف الثليك هابل وفستفل، ان زيادة

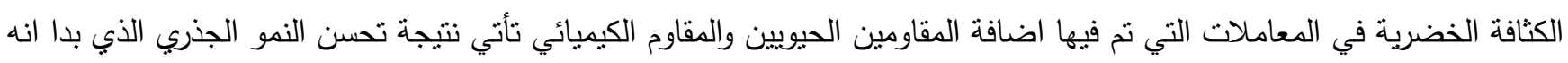
يعاني من اسوداد الجذور الرئيسة والجذيرات الثانوية في المعاملة بالفطر وحده (الثكل 3) وزيادة قدرة الجذور على النمو وامتصاص العناصر الغذائية وتحفيز صفات النمو الخضري منمنلة بالزيادة في قطر التاج وزيادة عدد الأوراق والوريقات وزيادة المساحة الورقية ودليل المساحة الورقية ومقاومة النبات للإصابات المرضية وتحمل الظروف القاسية ومنع حدوث أكسدة فيتامين C و E اللذين يوجدان في الكلوروبلاست مما يؤدي الى زيادة كفاءة التركيب الضوئي وبالتالي يحسن من نمو وتطور النبات (Jensen، 2004)، إذ ان فائدة البكتريا المحفزة لنمو النبات تتضمن زيادة نسبة انبات البذور ونمو الجذور بشكل جيد وزيادة في الانتاج والمساحة الورقية والمحتوى ئني الكلوروفيلي والمنغنيز والنتروجين والمحتوى البروتيني وحجم المجموع الجذري والخضري وبذللك نحصل على نباتات ذات مقاومة جيدة

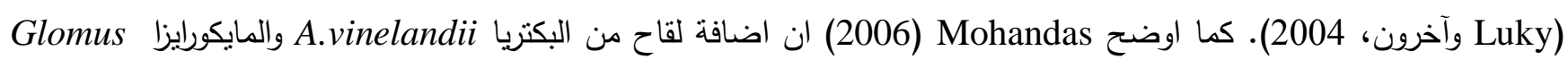
الى تربة نباتات الطماطح حققت زيادة معنوية في الحاصل والمساحة الورقية والوزن الجاف للمجموع الخضري ومحتوى عنصري النتروجين والفسفور بالمقارنة مع النباتات غير المعاملة. وان تفوق المعاملات المضاف لهات البكتريا يعود إلى المنافسة بين

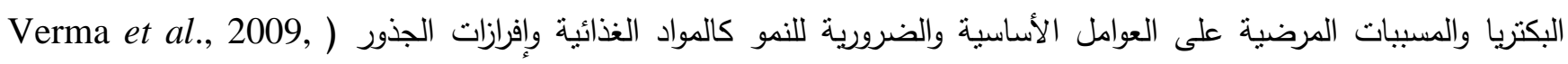
2010)، فضلاً عن مقدرة البكتريا على أنتاج العديد من المضادات الحيوية التي تحلل سايتوبلازم الخيوط الفطرية للمسببات المرضية

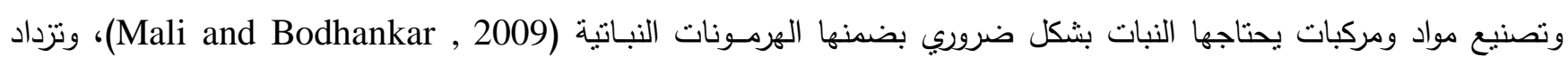
كذلك فعالية أنزيم Peroxidase الذي يؤدي إلى تقوية جدار الخلية ويحد من عملية اختراق المسبيات الفطرية للأنسجة النباتية 
وقد تعود زيادة الكثافة الخضرية إلى دور هذه المقاومات في زيادة جاهزية العديد من العناصر للنبات ومنها

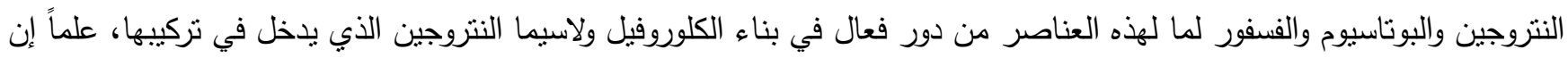
أكثر من نصف المحتوى الكلي للنبات من النتروجين يوجد في الكلوروبلاست فضلاً عن دور الفسفور في بناء المركبات الحاملة للطاقة التي تسهم في بناء جزيئات الكلوروفيل والبوتاسيوم الذي يعد واحدا من أهم العناصر التي تعمل كمنشطات للعديد من آليات التركيب الضوئي والتتفس، او قد يعود ذللك للتباين الوراثي بين الصنفين، وكذلك الى الاختلاف بين الاجناس والانواع والتغاير الوراثي

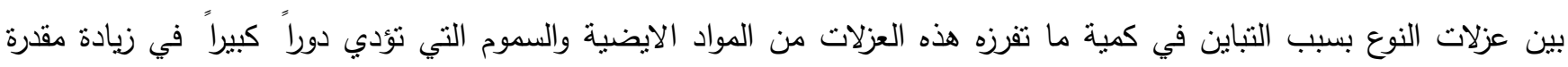

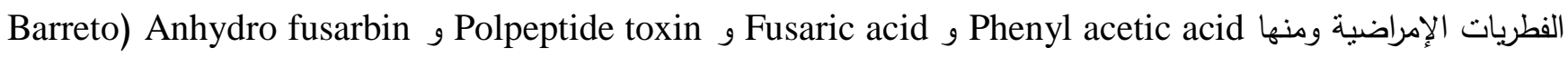
وآخرون،2003)، أو ربما يعود الى اختلاف العزلات في مقدتها على افراز الأنزيمات المحللة للبكتين والسيليلوز في المراحل المبكرة من الإصابة وهذه الأنزيمات تؤدي دوراً في اختراق العائل ومنها Pectinase و و Pectin methylesterase و و Phosphatase و و Laccase و و Lignin peroxidase والتي لها الاثر الكبير في إمراضية الفطر واختلاف العزلات

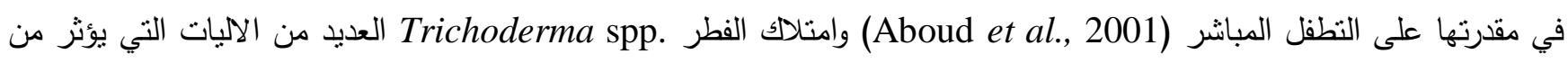
خلالها في الفطريات الممرضة للنبات (Chet and Chernin, 2002)، إذ اكد Jaime et al.,2011 ان منع موت نباتات الطماطم بنسبة 100\% في البيت الزجاجي. ويضم جنس البكتريا Pseudomonas عدة أنواع استخدم بنجاح في مكافحة الكثير من

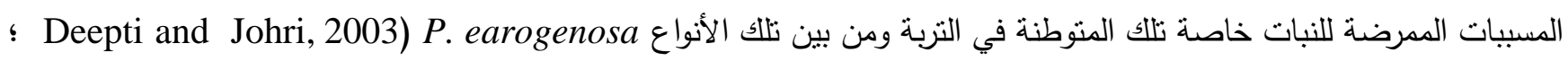

.(Thomas, 2004 

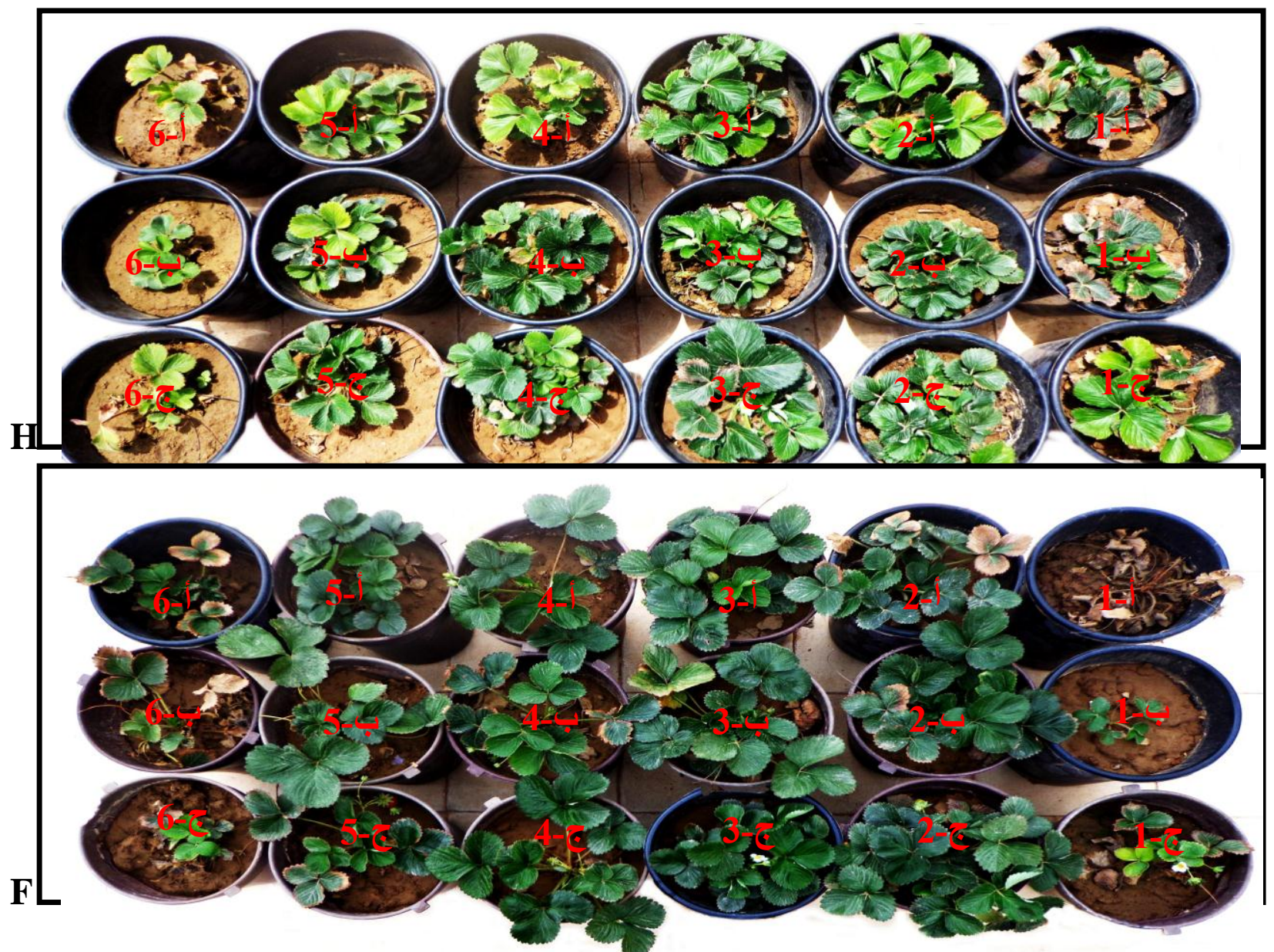

الثكل 1 : تأثير المعاملات المختلفة في حساسية صنفي الثليك هابل وفستفل، H: الصنف هابل، F: الصنف فستفل، أ-1:

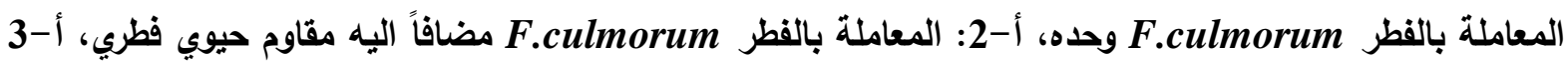
مضافاً اليه مقاوم حيوي بكتيري، أ-4 F.culmorum المعاملة بالفطر F.culmorum : المعاملة بالفطرة

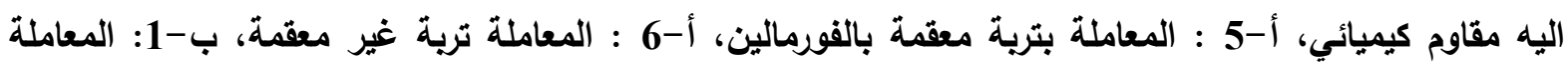
بالفطر .Cylindrocarpon spp. وحده، ب-2 : Cylindrocarpon spp. مضافاً اليه مقاوم حيوي فطري، ب-3: المعاملة بالفطر .Cylindrocarpon spp مضافاً اليه مقاوم حيوي بكتيري، ب-4: المعاملة

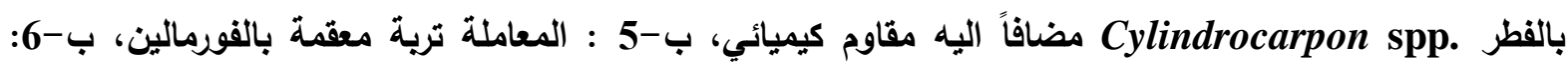

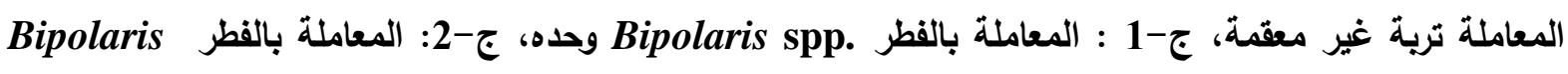

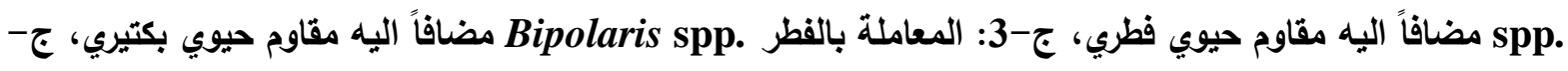

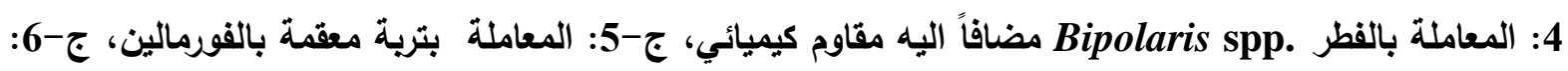
المعاملة بتربة غير معقمة. 
حساب شدة ظهور المرض (\%) للفطريات Cylindrocarpon spp. culmorum و و Bipolaris spp F. تبين النتائج في الجدول (2) ان اضافة المقاومين الحيوبين الفطري والبكتيري والمقاوم الكيميائي الى الفطرين

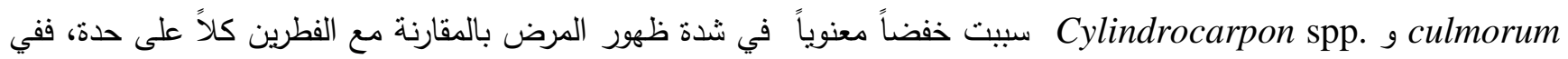

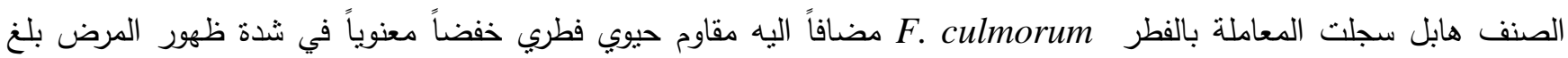
53.58\% في القراءة الاولى زاد الانخفاض في شدة ظهور المرض في القراءة الثانية، إذ بلغ 51.17\% بالمقارنة مع المعاملة بالفطر وحده وبلغت شدة ظهور المرض 69.52. culmorum

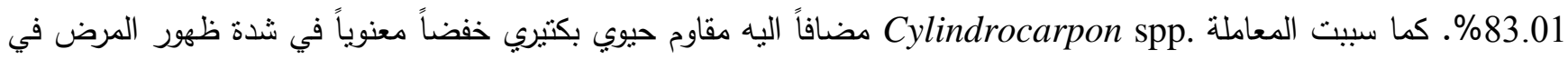
القراءة الاولى وبلغت 34.12\% كما زاد انخفاض شدة ظهور المرض في القراءة الثانية، وبلغ 22.45\% بالمقارنة مع المعاملة بالفطر بـاني

Cylindrocarpon spp. وحده إذ بلغت شدة ظهور المرض 51.85\% القراءة الاولى زادت في القراءة الثانية وبلغت 62.10\%. اما في الصنف فستفل سببت المعاملة بالفطر F. culmorum مضافاً اليه مقاوم حيوي فطري خفضاً معنوياً في شدة ظهور F. المرض بلغ 45.23\% في القراءة الاولى وزاد هذا الانخفاض في القراءة الثانية وبلغ 41.26\% بالمقارنة مع المعاملة بالفطري وحده، إذ بلغت شدة ظهور المرض 100 culmorum منذ الاسبوع الثاني لبدء تجربة البيت البلاستيكي غير المدفأ واظهرت المعاملة . Cylindrocarpon spp مضافاً اليه مقاوم حيوي بكتيري خفضاً معنوياً في شدة ظهور المرض في القراءة الاولى وزاد هذا الانخفاض في القراءة الثانية إذ بلغت 31.74\% و على التوالي بالمقارنة مع المعاملة بالفطر .Cylindrocarpon spp وحده، إذ بلغت شدة ظهور المرض 50.79\% للقراءة الاولى وزادت في القراءة الثانية وبلغت 61.11\%.

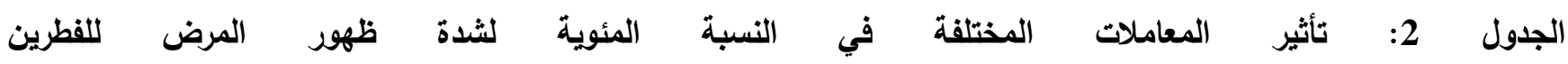
Cylindrocarpon spp. F. culmorum

\begin{tabular}{|c|c|c|c|c|}
\hline \multicolumn{4}{|c|}{ شدة ظهور المرض (\%)" } & \multirow{3}{*}{ 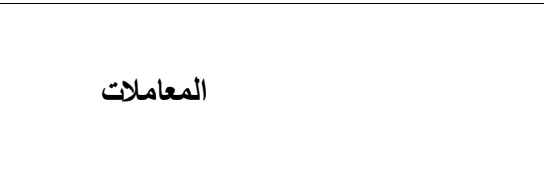 } \\
\hline \multicolumn{2}{|c|}{ 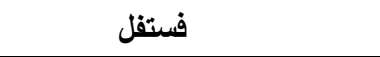 } & \multicolumn{2}{|c|}{ 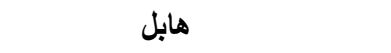 } & \\
\hline $2013 / 3 / 1$ & $2013 / 2 / 1$ & $2013 / 3 / 1$ & $2013 / 2 / 1$ & \\
\hline 100 & 100 & 83.01 & 69.52 & F. culmorum \\
\hline 41.26 & 45.23 & 51.17 & 53.58 & F. culmorum + مقاوم حيوي فطري \\
\hline 50.79 & 52.38 & 55.20 & 59.82 & F. culmorum + مقاوم حيوي بكتبري \\
\hline 48.50 & 52.38 & 57.96 & 59.82 & 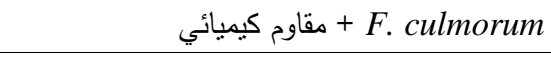 \\
\hline 61.11 & 50.79 & 62.10 & 51.58 & Cylindrocarpon spp. \\
\hline j23.01 & 39.68 هـ & j 30.27 & 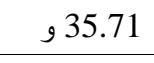 & Cylindrocarpon spp. مقاوم حيوي فطري \\
\hline$\tau 21.42$ & ز31.74 & ح 22.45 & j34.12 & Cylindrocarpon spp. + مقاوم حيوي بكتيري \\
\hline 32.53 & 9 & 30.65 & 37.71 & Cylindrocarpon spp. \\
\hline
\end{tabular}

• = الارقام التي تشترك بنفس الحرف او الحروف عمودياً ليس بينها فرق معنوي حسب اختبار دنكن متعدد الحدود عند مستوى احتمال 0.05. 
نتائج (الجدول 3) بينت ان المعاملة بالفطر .Bipolaris spp مضافاً اليه مقاوم كيميائي سببت خفضاً معنوياً في شدة ظهور المرض في الصنف هابل بلغ 20.15\% في القراءة الاولى وزاد الانخفاض في شدة ظهور المرض في القراءة الثانية وبلغ 64.81\% بالمقارنة مع المعاملة بالفطر .Bipolaris spp وحده إذ بلغت شدة ظهور المرض 5و 59.30\% في القراءة الاولى زادت هذه النسبة في القراءة الثانية إذ بلغت 70.37\%. كذلك في الصنف فستفل وسبيت المعاملة بالفطر .Bipolaris spp مضافاً اليه مقاوم كيميائي

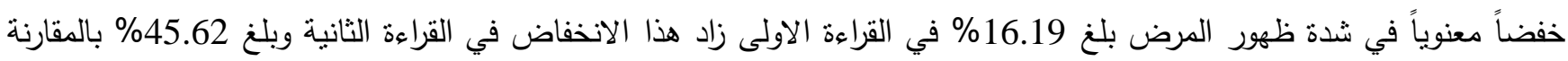
مع المعاملة بالفطر .Bipolaris spp وحده إذ بلغت شدة ظهور المرض 52.58\% في القراءة الاولى وزادت هذه النسبة في القراءة الثانية اذ بلغت 85.63\%

الجدول 3 : تأثير المعاملات المختلفة في النسبة المئوية لشدة ظهور المرض للفطر Bipolaris spp. لصنفي الشليك هابل وفستفل

\begin{tabular}{|c|c|c|c|c|}
\hline \multicolumn{4}{|c|}{ شدة ظهور المرض (\%)" } & \multirow{3}{*}{ 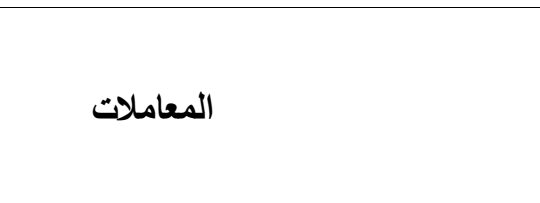 } \\
\hline \multicolumn{2}{|c|}{ فستفل } & \multicolumn{2}{|c|}{ هابل } & \\
\hline $2013 / 3 / 1$ & $2013 / 2 / 1$ & $2013 / 3 / 1$ & $2013 / 2 / 1$ & \\
\hline 85.63 & 52.58 & أ 70.37 & 59.30 & Bipolaris spp. \\
\hline 58.69 & 32.53 & 55.55 & 30.21 & Bipolaris spp. + مقاوم حيوي فطري \\
\hline 50.14 & 20.55 & 50.12 & 39.11 & Bipolaris spp. + مقاوم حيوي بكتيري \\
\hline 45.62 & 16.19 د & 64.81 & 20.15 & Bipolaris spp. \\
\hline
\end{tabular}

" الارقام التي تشترك بنفس الحرف او الحروف عمودياً ليس بينها فرق معنوي حسب اختبار دنكن متعدد الحدود عند مستوى احتمال

.0 .05

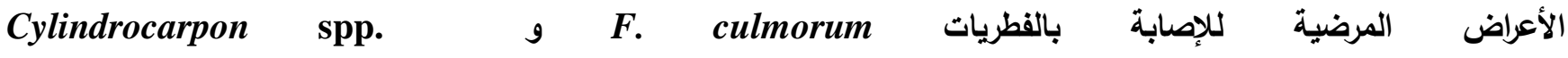

\section{Bipolaris spp.و}

F. culmorum تضمنت الأعراض المرضية على المجموع الخضري الثكل (2) للفطرين و .Cylindrocarpon spp بحصول اصفرار يبدأ من حافة الورقة يتبعه احتراق حوافِ الأوراق ينتشر بعدها ليشمل كامل الورقة فتموت الأوراق بعدها في الاصابات الثديدة وقد يظهر عليها أعراض التحزز إذ تظهر عروق الأوراق بلون غامق مقارنة مع باقي اجزاء الورقة التي تعاني من الاصفرار، ونتيجة إصابة الأوراق تتخفض كفاءتها في البناء الضوئي والسيطرة على الية فتح وغلق الثغور مما يؤدي الى انحناءها اللى الاعلى، ويمكن ان تصاب جميع الأوراق مسيبة موت النبات بالكامل نتيجة ندمير المجموع الخضري او قد تصاب بعض الأوراق دون الاخرى فتسبب انخفاض في الكثافة الخضرية للنبات نتيجة انخفاض عدد الأوراق والوريقات الثكل (1)، ويسبب الفطر .Bipolaris spp بالاضافة الى أعراض الاصفرار والاحتراق أعراض التبقعات لان هذا الفطر يصيب المجموع الجذري

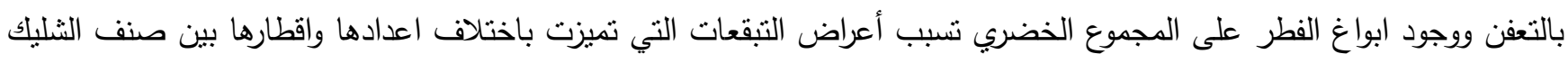
هابل وفستفل، ففي الصنف هابل ظهرت التبقعات على الأوراق المصفرة بلون ارجواني غير منتظمة الحواف اما في الصنف فستفل فتميزت التبقعات بلون كريمي في منتصف البقعة وتكون الحواف بلون ارجواني الثكل (4). 


$$
\text { هديل احمد العامري وآخرون }
$$

ان الأعراض المرضية الظاهرة على المجموع الخضري هي نتيجة إصابة المجموع الجذري بفطريات التعفن F. culmorum و Bipolaris spp. Cylindrocarpon spp. الجدر الخلوية وخروج محتويات الخلية للخارج وينتقل عبر الاوعية الناقلة الى منطقة التاج وتؤدي الى تعفنها ونتيجة ترسب السموم الفطرية فيها تؤدي الى تلونها وبعدها تصل الى الأوراق عبر الاوعية الناقلة مسببة ظهور أعراض الإصابة بالذبول الوعائي والذي سببه

تعفنات الجذور
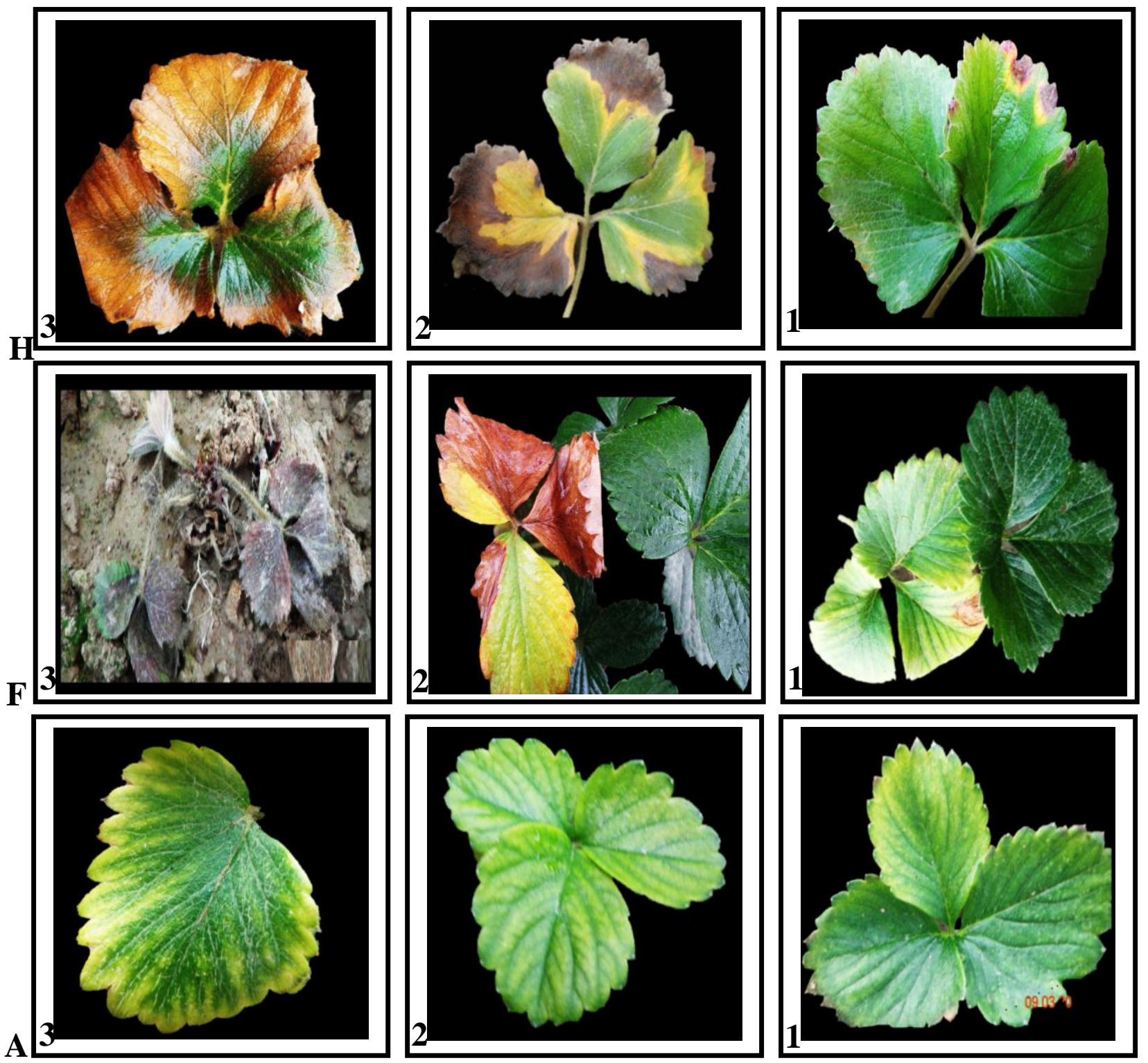

الثكل 2: أعراض الإصابة المرضية على أورلق صنفي الثليك هابل وفستفل، H : هابل، 1: بداية الإصابة اصفرار حواف الأوراق واحتراقها، 2: تقلم الإصابة بزيادة المساحة المصفرة والمحترقة من الورقة، 3: احتراق الورقة بالكامل، F: فستفل، 1: بداية الإصابة اصفرار الورقة واحتراقها وظهور تحزز فيها، 2: تقدم الاصفرار والاحترلق ليثمل كامل الورقة، 3: الإصابة 
الشديدة موت النبات بالكامل، A ظهور أعراض التحزز على صنف الشليك هابل وفستفل، 1: اصفرار خفيف وظهور التحزز، 2: اصفرار متوسط وظهور أعراض التحزز، 3: اصفرار غامق وظهور أعراض التحزز بوضوح.
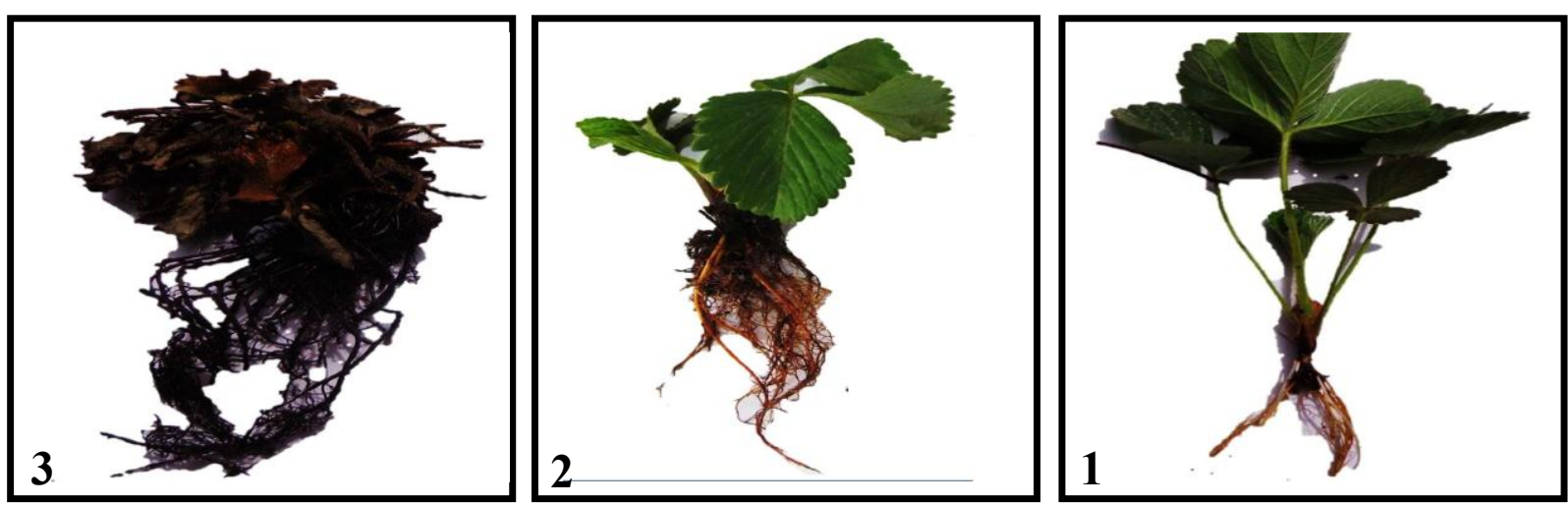

الثكل 3: أعراض التعفن على الجذور في نباتات صنفي الشليك هابل وفستفل، 1: جذر غير مصاب، 2: جذر يعاني من بداية ظهور التعفن متمثلة باسوداد الشعيرات الجذرية والجذور الثانوية، 3: جذر يعاني من مراحل متأخرة من التعفن متمثل باسوداد المنطقة الجذرية بالكامل والذي سبب موت النبات.

Bipolaris spp. حساب عدد البقع (بقعة/نبات) على الأوراق المصابة بالقطر

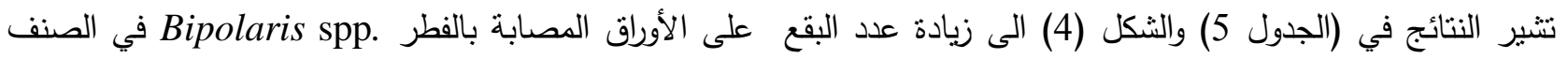
هابل عنها في الصنف فستفل، وسجلت المعاملة بالفطر .Bipolaris spp مضافاً اليه مقاوم كيميائي خفضاً معنوياً في عدد البقع بلغ 2.1 بقعة/نبات و 1.2 بقعة/نبات على التوالي لصنفي الثنليك هابل وفستفل بالمقارنة مع المعاملة بالفطر .Bipolaris spp. وحده، إذ بلغ متوسط عدد البقع 28 بقعة/نبات و 18.83 بقعة/نبات على التوالي لصنفي الثليك هابل وفستفل.

Bipolaris spp. حساب متوسط اقطار البقع (ملم) على الأولق المصابة بالفطر تشير النتائج في (الجدول 5) الى حدوث نقصان في منوسط اقطار البقع في الصنف هابل عنه في الصنف فستفل، ففي الصنف هابل سجلت المعاملة بالفطر .Bipolaris spp مضافاً اليه مقاوم كيميائي خفضاً معنوياً في منتسط اقطار البقع بلغ 0.75 ملم مقارنة مع المعاملة بالفطر .Bipolaris spp وحده إذ بلغ منوسط واقطار البقع 2.66 ملم. اما في الصنف فستفل فسجلت المعاملة بالفطر .Bipolaris spp. مضافاً اليه مقاوم حيوي بكتبري والمعاملة بالفطر مضافاً اليه مقاوم كيميائي خفضاً معنوياً في منوسط اقطار البقع بلغ 2.01 ملم و 2.04 ملم على التوالي ولم يكن بينهما فرقاً معنوياً مقارنة مع المعاملة بالفطر Bipolaris spp.

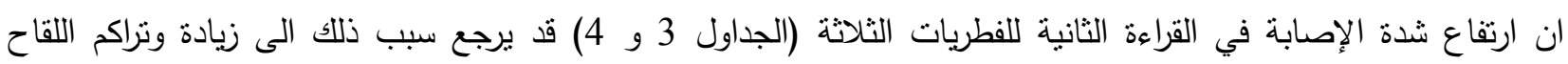
الفطري، فضلاً عن تحمله الظروف غير الملائمة لنموه بهيأة ابواغ كلاميدية، كما ان اختلاف شدة الإصابة بين الفطريات الثلاثة ربما يعود الىى اختلاف العزلات في مقدرتها على افراز العديد من المركبات الأيضية الثانوية السامة والأنزيمات المحللة للبكتين والسليلوز في المراحل الاولى من الإصابة التي لها الاثر الكبير في إمراضية الفطر واختراق الدفاعات البنائية للعائل (Lilja et al., 2006). كما ان سبب حساسية الاصناف للإصابة بالفطريات الممرضة قد يعود الى تحلل المركبات الدفاعية للنباتات Phytoalexins من قبل الإبل 


$$
\text { هديل احمد العامري وآخرون }
$$

and Pegg, الفطريات المهاجمة عن طريق افرازها لبعض الأنزيمات المحللة لهذه الدفاعات (Amtmann et al.,2008). وقد علات Sutherland (1995) من ينأثر الفطر المهاجم من خلال إفرازها لبعض الأنزيمات مثل Tomatinase كما ان ناتج تأثثر الفطر في مقار التمثيل الغذائي

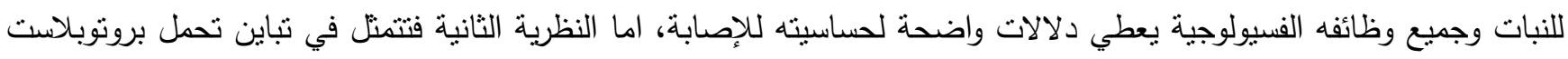
النبات لمركبات التمثيل الثانوية البروتينية الخارج خلوية Extracellular المنتجة من المسبب ومن هذه المركبات Fusaric Acid و

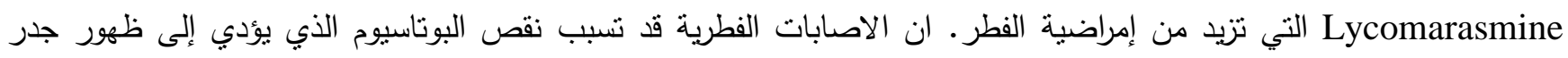

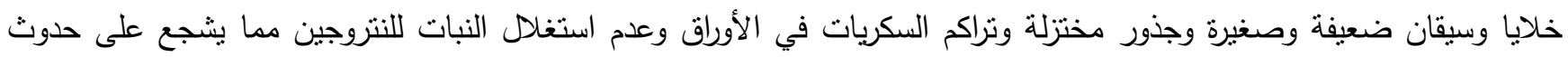

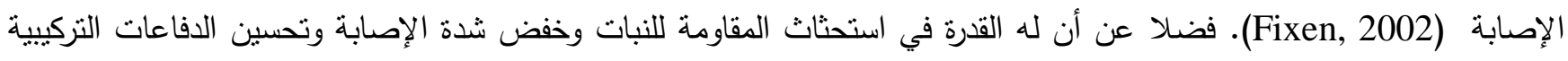
في النبات كما أن نقص البوتاسيوم يعمل على إبقاء فتحات الثغور مفتوحة لددة اطول مما يسهل دخول الفطريات الممرضة عن طريقها

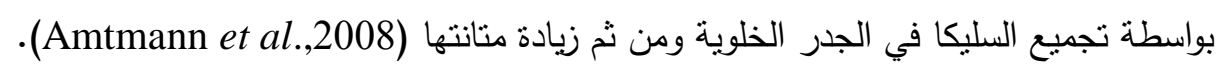

الجدول 5: تأثير المعاملات المختلفة في متوسط عدد البقع (بقعة/ورقة) واقطارها (ملم) للفطر .Bipolaris spp لصنفي الثليك هابل وفستفل

\begin{tabular}{|c|c|c|c|c|}
\hline \multicolumn{2}{|c|}{ فستفل } & \multicolumn{2}{|c|}{ 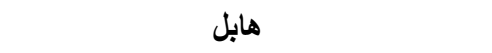 } & \multirow[b]{2}{*}{ 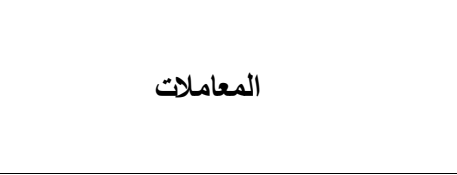 } \\
\hline متوسط اقطار البقع (ملم) & متوسط عدد البقع & متوسط اقطار البقع & متوسط عدد البقع & \\
\hline 3.06 & 18.83 & i 2.66 & $\{28$ & Bipolaris spp. \\
\hline 2.37 & 5.0 & 20 & 7.2 & . Bipolaris spp. مقاوم حيوي فطري \\
\hline 201 & 2.66 & ( & (4.5 - n & Bipolaris spp. + مقاوم حيوي بكتبري \\
\hline 2.04 & 1.2 & 0.75 & 2.1 & Bipolaris spp. \\
\hline
\end{tabular}
" = الارقام التي تتنرك بنفس الحرف او الحروف عمودياً ليس بينها فرق معنوي حسب اختبار دنكن متعدد الحدود عند مستوى احتمال 0.05. 

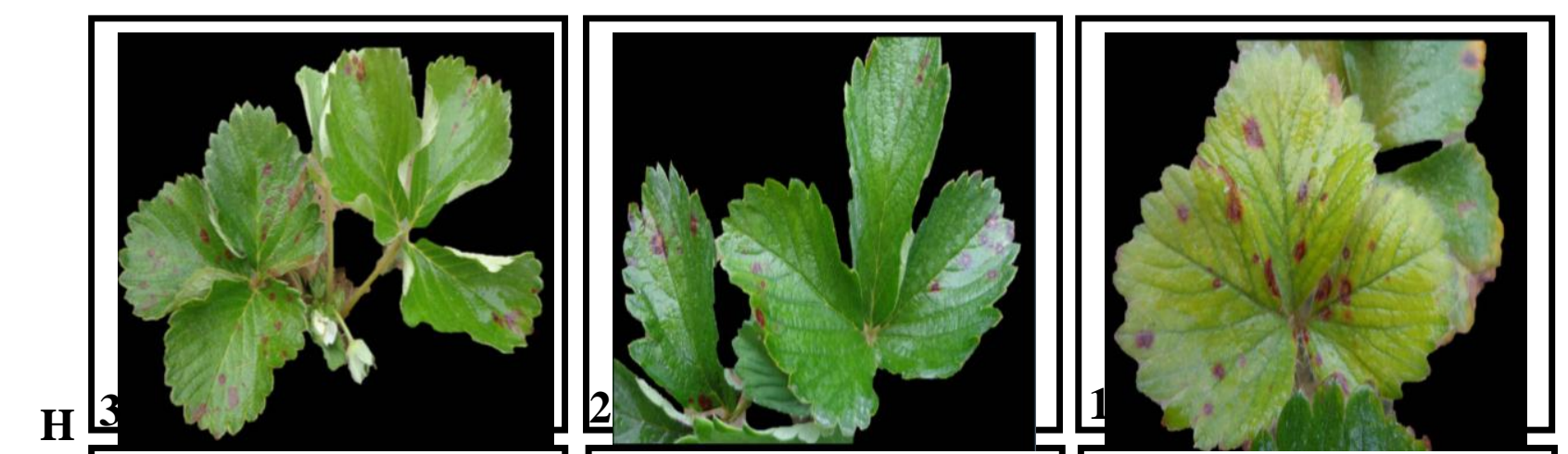

F 3
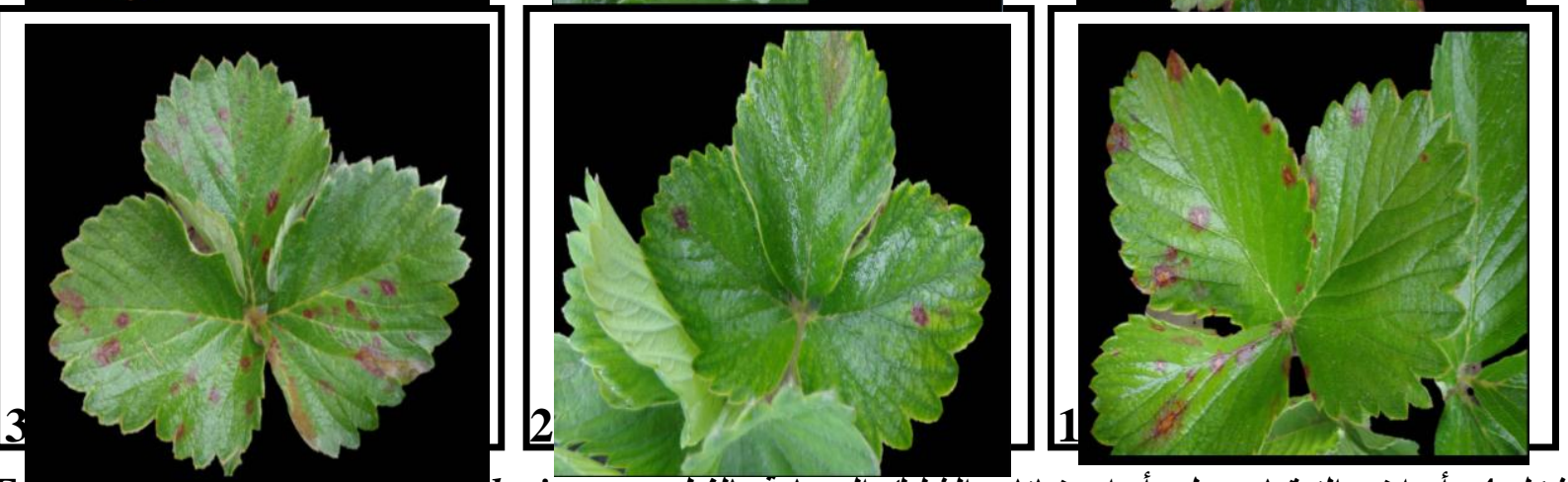

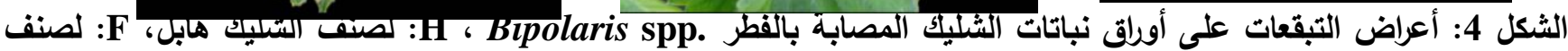

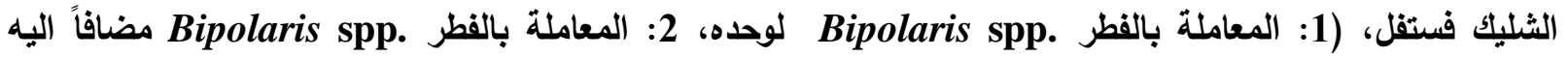
مقاوم كيميائي، 3: المعاملة بالقطر .Bipolaris spp. مضافاً اليه مقاوم حيوي فطري).

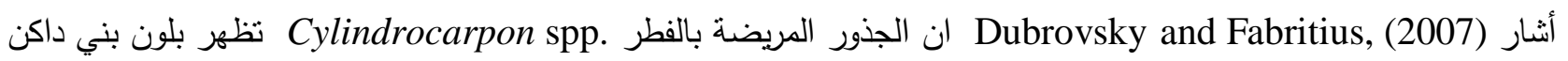
وترجع القدرة الإمراضية للفطر الىى انه يمكن أن ينمو في تراكيز منخفضة من الأكسجين، وله قدرة تتافسية عالية في أثناء النمو الفطري وإنبات جراثيمه السريع وقدرته على استخدام كل من النيتروجين العضوي وغير العضوي وينمو بسرعة حتى بتراكيز منخفضة العندئ العناصر

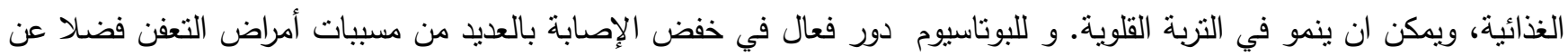

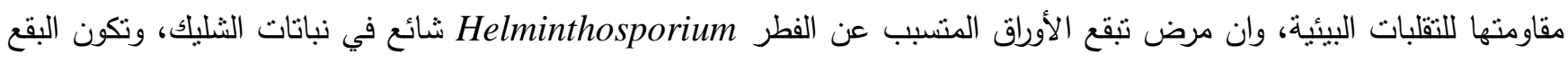

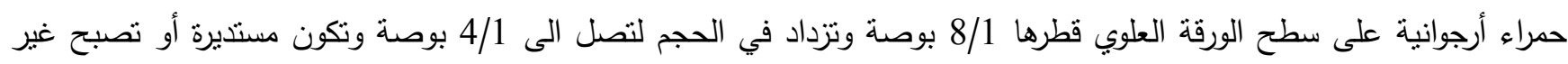
منتظمة إلى حد ما في وقت لاحق وتتطور البقع ليصبح لونها أبيضا رماديا في المركز ويحيط بها لون الوني أرجواني ونتلون حوافها باللون

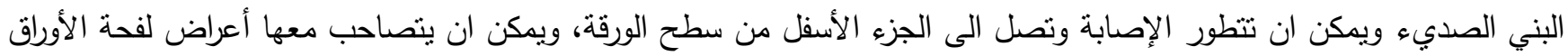
إذ تبدأ الإصابة على شكل بقع مستديرة لونها أرجواني مع مركز رمادي ثم يصبح المركز بني غامق بحيط بها منطقة أخف تنراوح بين

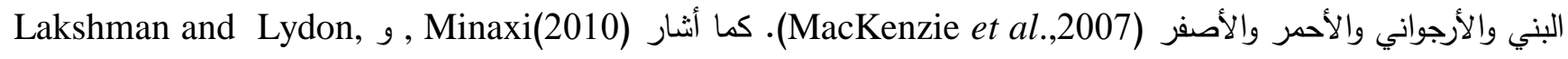
(2012) الى ان إنتاج المركبات الثانوية تتأس من قبل البكتريا P-RM earogenosa واظهرت

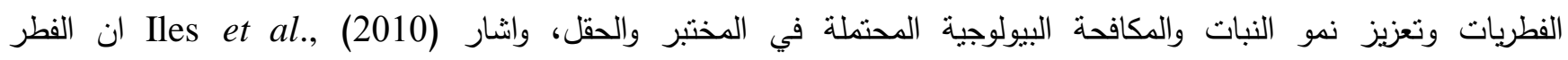
Cylindrocarpon destructans 


$$
\text { هديل احمد العامري وآخرون }
$$

أو عن طريق قمع الكائنات الحية الدقيقة المفيدة الأخرى. في حين اظهر المقاوم الحيوي Trichoderma harzianum كفاءة تثبيطية عالية في خفض إمراضية الفطر Fusarium oxysporum f. sp. Lycopersici المسبب لمرض الذبول على الطماطم في البيت

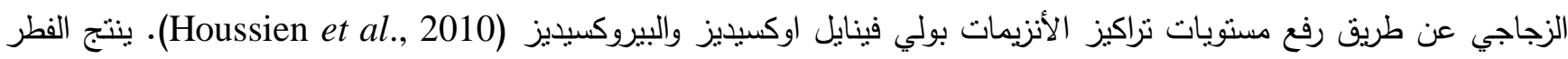
Pipolaris spp. قبل الفطر هو السم الذي يؤثز في عملية التنفس في النبات أثناء تثبيط الكترونات النقل وأنزيمات الأكسدة في المايتوكندريا وتعود أسباب أعراض التبقع والتقرح لهذه السموم، كما ينتج الفطر مركبين يسهمان في قتل النسيج النباتي يتكون كل منهما من تربين الأول

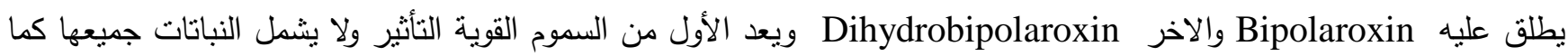

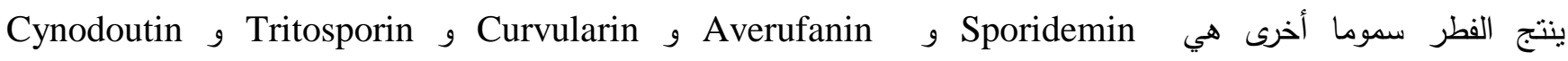

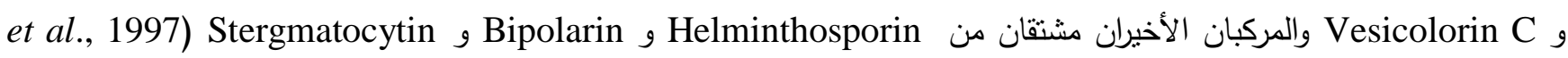
.(Lujan

\section{المصادر}

Agrios, G.N. (2005). "Plant Pathology". $5^{\text {th }}$ ed. Elsevier Academic Press, Burlington, U.S.A.

Amtmann, A.; Troufflard, S.; Armengaud, P. (2008). The effect of potassium nutrition on pest and disease resistance in plants, Physio. Plant.,13,1399-1405.

Barreto, D.; Babbitt, S.; Gally, M.; Perez, B. A. (2003). Nectria haematococca causing root rot in olive greenhouse plants revista de la Soiciedad Argentina de Horticultura, 32, 49 - 55.

Chet, I.; Chernin, L. (2002). "Biocontrol, Microbial Agents in soil, in Encyclopedia of Environmental Microbiology". G. Bitton, ed (New York : John Wiley and Sons ), pp. 450- 465.

Crosby, C.; Carpenter-Boggs, L.; Higgins, S.; Khadduri, N. (2011). Detection and control of Fusarium oxysporum and Cylindrocarpon destructans in forest nursery soils. Eur. J. Plant Pathol., 129, 637651.

Deepti, D.; Johri, B.N. (2003). Antifungal from Pseudomonas fluorescent : Biosynthesis and regulation. Current Sci. 85,1693-1703.

Domsch, K.H.; Gams, W.; Anderson, T.H. (1980). Compendium od soil fungi. 1(2), Academic press, London.

Don, G.H.; Apollo, O.G.; Scott, W.M. (2013). Macrophomina phaseolina and its association with strawberry crown rot in Australia, International, J. Fruit Sci., 13 (1-2), 149-155.

Dubrovsky, S.; Fabritius, A. (2007). Occurrence of Cylindrocarpon spp. in nursery grapevines in California. Phytopathol. Med., 46, 84-86.

Ellis, M.B. (1971). "Dematiaceous Hyphomycetes". Common wealth Mycological institute. Kew, Surrey, England.

Faize, M.; Faize, L.; Koike, N.; Ishizaka, M.; Ishii, H. (2004). Acibenzolar S-methyl-induced resistance to Japanese pear scab is associated with potentiation of multiple defense responses. J. Phytopathol., 94 (604), (Abs.).

Fang, X.L.; Phillips, D.; Li, H.; Sivasithamparam, K.; Barbetti, M.J. (2012). Severity of crown and root 


$$
\text { تأثثر بعض العوامل البايولوجية في إمراضيه................. }
$$

diseases of strawberry and associated fungal and oomycete pathogens in Western Australia. J. Aust. Plant Pathol., 40 (2), 109-119.

Fixen, P.E. (2002). Soil test levels in North America. Bettewr Crops. 86, 12-15.

Houssien, A.A.; Ahmed, S.M.; Ismail, A.A. (2010). Activation of Tomato Plant Defense Response Against Fusarium Wilt Disease Using Trichoderma harzianum and Salicylic Acid under Greenhouse Conditions. Res. J. Agric. and Biol. Sci., 6(3), 328-338.

Iles, T.M.; Ashton, D.H.; Kelliher, K.J.; Keane, P.J. (2010). The effect of Cylindrocarpon destructans on the growth of Eucalyptus regnans seedlings in air-dried and undried forest soil. Aus. J. Bot., 58 (2), 133140.

Jaime, M.; Valderrama, L.; Sánchez, S.; Herrera, R.; Besoain, X.; Pérez, M.L. (2011). Biological control of Rhizoctonia solani in tomatoes with Trichoderma harzianum mutants, Elec. J. Biotechn., 13 (2), 111.

Jensen, E. (2004). Seaweed fact or fancy. From the organic broadcaster. Published by noses the Midwest organic and sustainable education, From the broadcaster, 12 (3), 164-170.

Lakshman, D.K.; Lydon, J. (2012). Effect of overexpressing rsmA from Pseudomonas aeruginosa on virulence of select phytotoxin-producing strains of P. syringae. J. Phytopathol., 102, 575-587.

Leslie, J.F.; Summerell, B.A. (2006). "The Fusarium laboratory manual". Blackwell publishing, Ames, IA, USA.

Lilja, A.; Lozovaya, V.V.; Lygin, A.V.; Zernova, O.V.; Li, S.; Wind Holm, J.M.; Hartman, G.L. (2006). Lignin degradation by Fusarium solani. J. Plant Dis., 9, 77-82.

Lujan, R.M.; Cristaldo, L.O.; Carvalho, F.I.F.; Barbievi, R.L.; Kohli, M.M.; Dornelles, A.L.C; Handel, C.L.; Bered, F. (1997). Response of different subcultures of wheat callus to toxic filtrates of Helminthosporium sativum. J. Plant Pathol., 51, 39-43.

Luky, M.; Reed, E.; Glick, B.R. (2004). Applications of free living plant growth-promoting rhizobacteria. Review Antonie Van Leeuwenhoek. 86,1-25.

Mackenzie, S.J.; Seijo, T.E.; Legard, D.E.; Timmer, L.W.; Peres, N.A. (2007). Selection for pathogenicity to strawberry in populations of Colletotrichum gloeosporioides from native plants. J. Phytopathol., 97(9),1130- 1140.

Mali, G.V.; Bodhankar, M.G. (2009). Antifungal and phytohormone production potential of Azotobacter chroococcum isolates from Groundnut (Arachis hypogea L.). Asian J. Exp. Sci., 23 (1), 293-297. 


$$
\text { هديل احمد العامري وآخرون }
$$

Manici, L.M.; Caputo, F.; Baruzzi, G. (2005). Additional experiences to elucidate the microbial component of soil suppressiveness towards strawberry black root rot complex. Annals Applied Biol., 146(4), 421-431.

Minaxi, S.J. (2010). Characterization of Pseudomonas aeruginosa RM-3 as a potential biocontrol agent. J. Mycopathol., 170(3), 181-93.

Mohandas, S.(2006). Field response of tomato ( Lycopersicon esculentum ) to inoculation with a VAmycorrhizal fungus Glomus fasiculatum and with Azotobacter vinelandii, J. Plant and Soil, 98, $295-297$.

Moročko, I. (2006). Characterization of the strawberry pathogen Gnomonia fragariae, and Biocontrol possibilities. Diss. (sammanfattning/summary) Uppsala: Sveriges lantbruksuniv., Ph.D. Theses, Acta Universitatis Agriculturae Sueciae.

Nelson, P.E.; Toussoun, T.A.; Marasas, W.F.O. (1983). Fusarium species, an llustrated manual for identification, The Pennsylvania state university press, University park.73, pp. 1457-1462.

Pitt, J.I.; Hocking, A.D. (2007). Fungi and food spoilage, Academic Press, Sydney, Australia.

Saydam, C.; Copeu, M.; sezgin, E. (1973). Studies on the inoculation techniques of cotton wilt caused by Verticillium dehliae Kleb. Investigation on the laboratory inoculation techniques. J. Turk. Phytopatho.,2, 69-75.

Schroers, H.J.; Metka, Z.; Alenka, M.; Francois, H.; Pedro, W.C. (2008). Cylindrocarpon pauciseptatum sp. nov., with notes on Cylindrocarpon species with wide, predominantly 3septate macroconidia. Mycol. Res., 112, 82 - 92.

Thomas, B.(2004). Effect of Trichoderma colonization on auxin-mediated regulation of root elongation. J. Plant Growth Regul., 43 (23), 89-92.

Verma, J.P.; Yadav, J.; Tiwari, K.N.(2009). Effect of meosorhizobium and plant growth promoting rhizobacteria on nodulation and yields of chicpea. Biol. Forum. An Int. J., 1,11-14.

Verma, J.P.; Yadav, J.; Tiwari, K.N.; Lavakush, S.; Singh, V. (2010). Impact of plant growth promoting rhizobacteria on crop production. Inter. J. Agric. Res., 11, 954-983. 